\title{
Prostacyclin in the intensive care setting
}

\author{
D. Dunbar Ivy, MD \\ Department of Pediatrics, University of Colorado Denver School of Medicine, The Children's \\ Hospital, Aurora, CO
}

\begin{abstract}
The prostacyclins-prostanoids were one of the first medications used to treat pulmonary arterial hypertension (PAH). Three prostanoids have been developed to treat PAH: epoprostenol, treprostinil, and iloprost. In the acute setting, experience is growing, using the inhaled forms of these three medications. Inhalation may improve ventilation/perfusion matching, whereas in the intravenous form these medications may cause nonselective pulmonary vasodilation and may worsen ventilation/perfusion matching. Currently, there are no universal recommendations for dosing delivery of inhaled prostanoids to intubated patients in the intensive care unit setting.
\end{abstract}

\section{Keywords}

epoprostenol; treprostinil; iloprost; pulmonary arterial hypertension; congenital heart disease; critical care

\begin{abstract}
The term prostanoid encompasses members of the prostacyclin and prostaglandin families, such as prostacyclin $\mathrm{I}_{2}\left(\mathrm{PGI}_{2}\right)$ and prostaglandin $\mathrm{E}_{1}\left(\mathrm{PGE}_{1}\right)$. Prostanoids have potent vasodilatory and platelet anti-aggregatory properties, but are not selective to the pulmonary circulation if given via intravenous (IV) route (1). Pulmonary vasodilation reduces the workload of the right ventricle, increases pulmonary blood flow, and lowers the pulmonary artery pressure (PAP), resulting in the improvement of pulmonary arterial hypertension (PAH) symptoms and exercise capacity (2). Prostacyclins have been used to treat PAH since 1980 (3) with initial long-term therapy described in 1984 (4). Guidelines for medical therapy of PAH were recently updated in 2007, and include the use of $\mathrm{PGI}_{2}$ in the chronic setting (5).

$\mathrm{PGI}_{2}$ was initially discovered in 1976 (6). The cyclooxygenase enzymes COX-1 and COX-2 convert arachidonic acid to prostaglandin $\mathrm{H}_{2}$, the immediate precursor of $\mathrm{PGI}_{2}$. $\mathrm{PGI}_{2}$ is produced in endothelial cells from prostaglandin $\mathrm{H}_{2}$ by the action of the enzyme prostacyclin synthase. $\mathrm{PGI}_{2}$ subsequently acts on platelets and vascular smooth muscle. The platelet $\mathrm{G}$ protein-coupled receptor (prostacyclin receptor) is activated when it binds to $\mathrm{PGI}_{2}$. This activation, in turn, signals adenylcyclase to produce cyclic adenosine monophosphate. The cyclic adenosine monophosphate goes on to inhibit platelet activation and also counteracts any increase in cytosolic calcium levels, which would result from thromboxane $\mathrm{A}_{2}$ binding. $\mathrm{PGI}_{2}$ also binds to smooth muscle prostacyclin receptors and, in the same manner, raises cyclic adenosine monophosphate levels in the cytosol leading to activation of protein kinase A. Protein kinase A then continues the cascade by inhibiting myosin light-chain kinase, which leads to smooth muscle relaxation and vasodilation. $\mathrm{PGI}_{2}$
\end{abstract}

Copyright $₫ 2010$ by the Society of Critical Care Medicine and the World Federation of Pediatric Intensive and Critical Care Societies ivy.dunbar@tchden.org. 
is nonenzymatically hydrated to 6-keto $\mathrm{PGF}_{1 \alpha}$, and then quickly converted to the major metabolite, 2, 3-dinor-6-keto $\mathrm{PGF}_{1 \alpha}$.

$\mathrm{PGI}_{2}$ was once thought to be a circulating hormone that regulated platelet-vasculature interactions, but the rate of secretion into circulation coupled with the short half-life indicate that $\mathrm{PGI}_{2}$ functions locally. Shear stress increases production of $\mathrm{PGI}_{2}$ by increasing $\mathrm{COX}$ and prostacyclin synthase. However, long-term stimulation of the prostacyclin receptor leads to desensitization through receptor-mediated mechanisms (1). Studies have shown that milrinone, a PDE3 inhibitor, potentiates the pulmonary vasodilator effects of $\mathrm{PGI}_{2}$ and may be of clinical benefit (Fig. 1) (7).

Adults with idiopathic pulmonary arterial hypertension (IPAH) and children with congenital heart disease demonstrate an imbalance in the biosynthesis of thromboxane $\mathrm{A}_{2}$ and $\mathrm{PGI}_{2}(8$, 9). Likewise, adults and children with severe pulmonary hypertension show diminished prostacyclin synthase expression in the lung vasculature (10). $\mathrm{PGI}_{2}$ administered over the long term has been shown to improve survival and quality of life in adults and children with IPAH (11-16).

Three prostanoids are currently approved by the Food and Drug Administration (FDA) for the treatment of PAH in the United States (2). Epoprostenol (Flolan; GlaxoSmithKline, Research Triangle Park, NC), synthetic $\mathrm{PGI}_{2}$, is approved for administration by continuous IV infusion through a central venous catheter. Treprostinil (Remodulin; United Therapeutics, Research Triangle Park, NC), a PGI $_{2}$ analog with similar hemodynamic effects to epoprostenol, is approved for administration by either continuous IV infusion through a central venous catheter or continuous subcutaneous infusion, and recently was approved for inhalation in the outpatient setting. Iloprost (Ventavis; Actelion Pharmaceuticals, South San Francisco, CA) is also a $\mathrm{PGI}_{2}$ analog that is approved for inhalation treatment of PAH. Side effects common to all prostanoids include headache, flushing, hypotension, jaw pain with initial mastication, diarrhea, nausea, a blotchy erythematous rash, and musculoskeletal aches and pain predominantly involving the legs and feet. The severity of these side effects may vary among patients and with dose escalation.

\section{Epoprostenol}

Epoprostenol causes pulmonary and systemic vasodilation and inhibits vascular proliferation and platelet aggregation (2). It was the first prostanoid approved by the FDA to treat PAH in 1995, and is indicated for the treatment of PAH in World Health Organization Functional Class III-IV patients. Intravenous epoprostenol demonstrated efficacy in two prospective, open-label, randomized trials comparing epoprostenol and conventional therapy to conventional therapy alone with improvement in exercise capacity $(11,17)$. Intravenous epoprostenol is initiated at $1 \mathrm{ng} / \mathrm{kg} / \mathrm{min}$ to $3 \mathrm{ng} / \mathrm{kg} / \mathrm{min}$ and gradually increased over several months to a dose of $30 \mathrm{ng} / \mathrm{kg} / \mathrm{min}$ to $\geq 80 \mathrm{ng} / \mathrm{kg} / \mathrm{min}$. It is crucial to individually titrate dose depending on the therapeutic response, degree of systemic effects, and emergence of prostanoid-related side effects. Epoprostenol has a short half-life of 2 mins to 3 mins and is unstable at room temperature. Any rapid rate decrease or interruption of the infusion due to either an occluded catheter or pump malfunction can cause severe rebound pulmonary hypertension and death $(18,19)$.

In a recent study (13), 77 children diagnosed with IPAH between 1982 and 1995 were followed up through 2002. Survival for all children treated with epoprostenol $(\mathrm{n}=35)$ at 1 $\mathrm{yr}, 5 \mathrm{yrs}$, and $10 \mathrm{yrs}$ was $94 \%, 81 \%$, and $61 \%$, respectively, whereas treatment success was $83 \%, 57 \%$, and $37 \%$, respectively. These results are similar to those found in adults with IPAH treated with IV epoprostenol (16). Due to the development of tolerance, the dose of 
IV epoprostenol is incrementally increased and is usually higher in children than adults. Continuous epoprostenol has also been used in a smaller cohort of patients with PAH associated with congenital heart disease (20). Prostacyclin has also been studied in combination with bosentan (21) and sildenafil (22). In the acute setting, IV epoprostenol may be a potent pulmonary vasodilator and may have beneficial effects, in addition to those of inhaled nitric oxide. Care should be taken in patients with suspicion of pulmonary venous disease, as IV epoprostenol in this setting may markedly worsen pulmonary edema. Furthermore, up-titration of IV epoprostenol in patients with pneumonia and pulmonary hypertension may worsen ventilation/perfusion matching and result in worsening oxygenation.

Because IV epoprostenol is a nonselective pulmonary vasodilator, it may worsen ventilation/ perfusion matching, and because its effects are not limited to the pulmonary circulation, it may cause systemic hypotension. Thus, interest has grown in the delivery of epoprostenol via the inhaled route (Fig. 2) (23, 24). At low to moderate doses, inhaled epoprostenol may improve perfusion to well-ventilated areas and more selectively lower PAP and pulmonary vascular resistance (PVR). Inhaled epoprostenol has been studied in a small series of neonates with persistent pulmonary hypertension of the newborn. Kelly et al (25) studied inhaled epoprostenol in neonates with persistent pulmonary hypertension of the newborn who failed inhaled nitric oxide and lung recruitment strategies. In these patients who had an oxygenation index of $>25$ and received inhaled nitric oxide, continuous inhaled epoprostenol at a dose of $50 \mathrm{ng} / \mathrm{kg} / \mathrm{min}$ caused a rapid and marked decrease in the oxygenation index without lowering systemic arterial pressure (Fig. 3). Because of the cost of inhaled nitric oxide, some centers have increased usage of inhaled epoprostenol. However, the ideal delivery system has not been developed and most systems alter delivered tidal volume by the ventilator.

\section{Treprostinil}

Treprostinil was approved by the FDA in 2002 as a continuous subcutaneous infusion for the treatment of PAH. Sub-cutaneous treprostinil demonstrated safety and efficacy in two randomized, placebo-controlled trials in PAH World Health Organization Class II-IV patients with improvement in exercise capacity (26). Recently, a large open-label trial of 860 patients reported a long-term survival benefit of treprostinil in patients with IPAH comparable to the survival benefit of epoprostenol, relative to published registry survival curves (27); however, subcutaneous infusion site pain was a treatment-limiting factor for some patients despite the clinical benefit. Survival in IPAH was $91 \%$ at $1 \mathrm{yr}$ and $72 \%$ at 4 yrs. A bioequivalence study comparing IV and subcutaneous routes of administration was conducted, and based on the results, IV treprostinil received FDA approval in 2004 for patients who are not able to tolerate subcutaneous infusion (28). In addition, as of February 2008 , treprostinil was also indicated to diminish the clinical deterioration in patients requiring transition from epoprostenol.

IV treprostinil has fewer side effects than IV epoprostenol, but there are no studies comparing efficacy (29-33). Intravenous treprostinil is initiated at 1 to $3 \mathrm{ng} / \mathrm{kg} / \mathrm{min}$ and gradually increased by $1 \mathrm{ng} / \mathrm{kg} / \mathrm{min}$ to $2 \mathrm{ng} / \mathrm{kg} / \mathrm{min}$ two to three times weekly to a chronic dose of $80 \mathrm{ng} / \mathrm{kg} / \mathrm{min}$ to $\geq 120 \mathrm{ng} / \mathrm{kg} / \mathrm{min}$. Again, it is crucial to individually titrate the patient's dose depending on the emergence of prostanoid-related side effects and therapeutic response (34). Inhaled treprostinil has been studied in the chronic outpatient setting leading to its recent approval in 2009, but little is known about the use of inhaled treprostinil in the acute setting. In the outpatient setting, inhaled treprostinil administered four times a day lowers PAP and PVR at the same time improving 6-min walk distance (35-38). 


\section{lloprost}

Iloprost received approval for the treatment of PAH in the United States in December 2004. This medication is administered by nebulization six to nine times a day. Iloprost has been shown to improve hemodynamics and exercise capacity. Iloprost requires patient cooperation with the treatment administration lasting $10 \mathrm{mins}$ to $15 \mathrm{mins}$, which is difficult for young children (39-45). As mentioned previously, one benefit of inhaled delivery is that the systemic side effects, including systemic hypotension, should be limited. In a select patient population, iloprost may benefit children as add-on therapy or to replace IV therapy in children with repeated central catheter infections. However, some children may develop reactive airways obstruction, limiting usefulness of this therapy (Fig. 4) (40). Iloprost has also been studied in combination with bosentan and sildenafil, among others (41).

In the acute setting, iloprost lowers mean PAP and improves systemic oxygen saturation and is as effective in lowering the ratio of PVR to systemic vascular resistance as inhaled nitric oxide (Fig. 5) (46). In a study of 46 adult patients with pulmonary hypertension primarily related to mitral or aortic valve disease, both inhaled nitric oxide and iloprost were effective in lowering mean PAP and PVR and led to increases in cardiac output. However, iloprost at a dose of $20 \mu \mathrm{g}$ over 4-6 mins caused significantly greater reductions in mean PAP and PVR than inhaled nitric oxide (47). In a recent pediatric study in the acute care setting of postoperative congenital heart disease, Limsuwan and colleagues (48) evaluated the effects of iloprost in 12 children in the intensive care setting. Utilizing a dose of $500 \mathrm{ng} / \mathrm{kg} / \mathrm{dose}$ to $2000 \mathrm{ng} / \mathrm{kg} /$ dose over 10 mins every 30 mins up to five times, the authors found that iloprost caused selective pulmonary vasodilation without worsening oxygenation. Further study in the acute care setting is warranted (Fig. 6) (48). Some centers have noted systemic hypotension during administration of higher doses of inhaled iloprost in the intensive care unit setting.

\section{Other Prostanoids}

Finally, beraprost, an oral prostacyclin analog, is currently under evaluation. Although beneficial effects have been noted in short-term trials (49), these benefits may be attenuated with prolonged treatment $(50,51)$. An oral prostacyclin analog of treprostinil is currently under study as well. Before the development of $\mathrm{PGI}_{2}$ and its analogs, IV $\mathrm{PGE}_{1}$ was used for the treatment of postoperative pulmonary hypertension (52). Kermode and colleagues (52) studied the use of IV $\mathrm{PGE}_{1}$ in postoperative congenital heart disease and found it to be effective, but the effects were not selective to the pulmonary circulation.

In summary, the prostacyclins-prostanoids were one of the first medications used to treat PAH. Unfortunately, in the IV form, these medications cause nonselective pulmonary vasodilation and may worsen ventilation/perfusion matching. Recent development of the inhaled route of delivery has renewed interest in this class of pulmonary vasodilators.

\section{Classification of Recommendations and Level of Evidence}

1. Evidence and/or general agreement that a given treatment or procedure is beneficial, useful, effective; expert opinion

2. Evidence and/or general agreement that a given treatment or procedure is beneficial, useful, effective; data derived from multiple randomized clinical trials or meta-analysis

3. Evidence and/or general agreement that a given treatment or procedure is beneficial, useful, effective; data derived from a single, randomized trial or large nonrandomized studies 
4. Evidence and/or general agreement that a given treatment or procedure is beneficial, useful, effective; data derived from a single, randomized trial or large nonrandomized studies

5. Usefulness/efficacy is less well-established by evidence/opinion; consensus of opinion of the experts and/or small studies, retrospective studies, registries

\section{Acknowledgments}

Dr. Ivy has received grants or funding from the National Institutes of Health, United Therapeutics Corp., and Gilead; he holds consultancies with United Therapeutics Corp., Atelion Pharmaceuticals, and Gilead.

\section{REFERENCES}

1. Vane J, Corin RE. Prostacyclin: A vascular mediator. Eur J Vasc Endovasc Surg. 2003; 26:571-578. [PubMed: 14603414]

2. Gomberg-Maitland M, Olschewski H. Prostacyclin therapies for the treatment of pulmonary arterial hypertension. Eur Respir J. 2008; 31:891-901. [PubMed: 18378784]

3. O'Grady J, Warrington S, Moti MJ, et al. Effects of intravenous infusion of prostacyclin (PGI2) in man. Prostaglandins. 1980; 19:319-332. [PubMed: 6992228]

4. Higenbottam T, Wheeldon D, Wells F, et al. Long-term treatment of primary pulmonary hypertension with continuous intravenous epoprostenol (prostacyclin). Lancet. 1984; 1:1046-1047. [PubMed: 6143976]

5. Badesch DB, Abman SH, Simonneau G, et al. Medical therapy for pulmonary arterial hypertension: Updated ACCP evidence-based clinical practice guidelines. Chest. 2007; 131:1917-1928. [PubMed: 17565025]

6. Moncada S, Gryglewski R, Bunting S, et al. An enzyme isolated from arteries transforms prostaglandin endoperoxides to an unstable substance that inhibits platelet aggregation. Nature. 1976; 263:663-665. [PubMed: 802670]

7. Rashid N, Morin FC 3rd, Swartz DD, et al. Effects of prostacyclin and milrinone on pulmonary hemodynamics in newborn lambs with persistent pulmonary hypertension induced by ductal ligation. Pediatr Res. 2006; 60:624-629. [PubMed: 16988189]

8. Christman BW, McPherson CD, Newman JH, et al. An imbalance between the excretion of thromboxane and prostacyclin metabolites in pulmonary hypertension. N Engl J Med. 1992; 327:70-75. [PubMed: 1603138]

9. Adatia I, Barrow SE, Stratton PD, et al. Thromboxane A2 and prostacyclin biosynthesis in children and adolescents with pulmonary vascular disease. Circulation. 1993; 88:2117-122. [PubMed: 8222105]

10. Tuder RM, Cool CD, Geraci MW, et al. Pros-tacyclin synthase expression is decreased in lungs from patients with severe pulmonary hypertension. Am J Respir Crit Care Med. 1999; 159:19251932. [PubMed: 10351941]

11. Barst RJ, Rubin LJ, Long WA, et al. A comparison of continuous intravenous epoprostenol (prostacyclin) with conventional therapy for primary pulmonary hypertension. The Primary Pulmonary Hypertension Study Group. N Engl J Med. 1996; 334:296-302. [PubMed: 8532025]

12. Barst RJ, Maislin G, Fishman AP. Vasodilator therapy for primary pulmonary hypertension in children. Circulation. 1999; 99:1197-1208. [PubMed: 10069788]

13. Yung D, Widlitz AC, Rosenzweig EB, et al. Outcomes in children with idiopathic pulmonary arterial hypertension. Circulation. 2004; 110:660-665. [PubMed: 15289375]

14. Ivy DD, Doran A, Claussen L, et al. Weaning and discontinuation of epoprostenol in children with idiopathic pulmonary arterial hypertension receiving concomitant bosentan. Am J Cardiol. 2004; 93:943-946. [PubMed: 15050507]

15. Lammers AE, Hislop AA, Flynn Y, et al. Epoprostenol treatment in children with severe pulmonary hypertension. Heart. 2007; 93:739-743. [PubMed: 17065181]

16. McLaughlin VV, Shillington A, Rich S. Survival in primary pulmonary hypertension: The impact of epoprostenol therapy. Circulation. 2002; 106:1477-1482. [PubMed: 12234951] 
17. Sitbon OHM, Nunes H, Parent F, et al. Long-term intravenous epoprostenol infusion in primary pulmonary hypertension: Prognostic factors and survival. J Am Coll Cardiol. 2002; 40:780-788. [PubMed: 12204511]

18. Rubin LJ, Mendoza J, Hood M, et al. Treatment of primary pulmonary hypertension with continuous intravenous prostacyclin (epoprostenol). Results of a randomized trial. Ann Intern Med. 1990; 112:485-491. [PubMed: 2107780]

19. Barst RJ, Rubin LJ, McGoon MD, et al. Survival in primary pulmonary hypertension with longterm continuous intravenous prostacyclin. Ann Intern Med. 1994; 121:409-415. [PubMed: 8053614]

20. Rosenzweig EB, Kerstein D, Barst RJ. Long-term prostacyclin for pulmonary hypertension with associated congenital heart defects. Circulation. 1999; 99:1858-1865. [PubMed: 10199883]

21. Humbert M, Barst RJ, Robbins IM, et al. Combination of bosentan with epoprostenol in pulmonary arterial hypertension: BREATHE-2. Eur Respir J. 2004; 24:353-359. [PubMed: 15358690]

22. Simonneau G, Rubin LJ, Galie N, et al. Addition of sildenafil to long-term intravenous epoprostenol therapy in patients with pulmonary arterial hypertension: A randomized trial. Ann Intern Med. 2008; 149:521-530. [PubMed: 18936500]

23. Max M, Rossaint R. Inhaled prostacyclin in the treatment of pulmonary hypertension. Eur $\mathbf{J}$ Pediatr. 1999; 158(Suppl 1):S23-S26. [PubMed: 10592095]

24. Katz SL, Adatia I, Louca E, et al. Nebulized therapies for childhood pulmonary hypertension: An in vitro model. Pediatr Pulmonol. 2006; 41:666-673. [PubMed: 16703580]

25. Kelly LK, Porta NF, Goodman DM, et al. Inhaled prostacyclin for term infants with persistent pulmonary hypertension refractory to inhaled nitric oxide. J Pediatr. 2002; 141:830-832. [PubMed: 12461501]

26. Simonneau G, Barst RJ, Galie N, et al. Continuous subcutaneous infusion of treprostinil, a prostacyclin analogue, in patients with pulmonary arterial hypertension: A double-blind randomized, placebo-controlled trial. Am J Respir Crit Care Med. 2002; 165:800-804. [PubMed: 11897647]

27. Barst RJ, Galie N, Naeije R, et al. Long-term outcome in pulmonary arterial hypertension patients treated with subcutaneous treprostinil. Eur Respir J. 2006; 28:1195-1203. [PubMed: 16899485]

28. Laliberte K, Arneson C, Jeffs R, et al. Pharmacokinetics and steady-state bioequivalence of treprostinil sodium (Remodulin) administered by the intravenous and subcutaneous route to normal volunteers. J Cardiovasc Pharmacol. 2004; 44:209-214. [PubMed: 15243302]

29. Widlitz AC, McDevitt S, Ward GR, et al. Practical aspects of continuous intravenous treprostinil therapy. Crit Care Nurse. 2007; 27:41-42. 44-45, 47-50. quiz, 51. [PubMed: 17389412]

30. Ivy DD, Claussen L, Doran A. Transition of stable pediatric patients with pulmonary arterial hypertension from intravenous epoprostenol to intravenous treprostinil. Am J Cardiol. 2007; 99:696-698. [PubMed: 17317374]

31. Doran A, Harris S, Goetz B. Advances in prostanoid infusion therapy for pulmonary arterial hypertension. J Infus Nurs. 2008; 31:336-345. [PubMed: 19018187]

32. Centers for Disease Control and Prevention (CDC). MMWR Morb Mortal Wkly Rep. Vol. 56. 2007. Bloodstream infections among patients treated with intravenous epoprostenol or intravenous treprostinil for pulmonary arterial hypertension—seven sites, United States, 2003-2006; p. 170-172.

33. Doran AK, Ivy DD, Barst RJ, et al. Guidelines for the prevention of central venous catheter-related blood stream infections with prostanoid therapy for pulmonary arterial hypertension. Int J Clin Pract Suppl. 2008:5-9. [PubMed: 18638170]

34. Tapson VF, Gomberg-Maitland M, McLaughlin VV, et al. Safety and efficacy of IV treprostinil for pulmonary arterial hypertension: A prospective, multicenter, open-label, 12-week trial. Chest. 2006; 129:683-688. [PubMed: 16537868]

35. Channick RN, Olschewski H, Seeger W, et al. Safety and efficacy of inhaled treprostinil as add-on therapy to bosentan in pulmonary arterial hypertension. J Am Coll Cardiol. 2006; 48:1433-1437. [PubMed: 17010807] 
36. Voswinckel R, Enke B, Reichenberger F, et al. Favorable effects of inhaled treprostinil in severe pulmonary hypertension: Results from randomized controlled pilot studies. J Am Coll Cardiol. 2006; 48:1672-1681. [PubMed: 17045906]

37. Voswinckel R, Reichenberger F, Enke B, et al. Acute effects of the combination of sildenafil and inhaled treprostinil on haemodynamics and gas exchange in pulmonary hypertension. Pulm Pharmacol Ther. 2008; 21:824-832. [PubMed: 18657627]

38. Voswinckel R, Reichenberger F, Gall H, et al. Metered dose inhaler delivery of treprostinil for the treatment of pulmonary hypertension. Pulm Pharmacol Ther. 2009; 22:50-56. [PubMed: 19071225]

39. Hoeper MM, Schwarze M, Ehlerding S, et al. Long-term treatment of primary pulmonary hypertension with aerosolized iloprost, a prostacyclin analogue. N Engl J Med. 2000; 342:18661870. [PubMed: 10861321]

40. Ivy DD, Doran AK, Smith KJ, et al. Short-and long-term effects of inhaled iloprost therapy in children with pulmonary arterial hypertension. J Am Coll Cardiol. 2008; 51:161-169. [PubMed: 18191742]

41. McLaughlin VV, Oudiz RJ, Frost A, et al. Randomized study of adding inhaled iloprost to existing bosentan in pulmonary arterial hypertension. Am J Respir Crit Care Med. 2006; 174:1257-1263. [PubMed: 16946127]

42. Olschewski H, Simonneau G, Galie N, et al. Inhaled iloprost for severe pulmonary hypertension. N Engl J Med. 2002; 347:322-329. [PubMed: 12151469]

43. Ewert R, Opitz CF, Wensel R, et al. Continuous intravenous iloprost to revert treatment failure of first-line inhaled iloprost therapy in patients with idiopathic pulmonary arterial hypertension. Clin Res Cardiol. 2007; 96:211-217. [PubMed: 17294349]

44. Hallioglu O, Dilber E, Celiker A. Comparison of acute hemodynamic effects of aerosolized and intravenous iloprost in secondary pulmonary hypertension in children with congenital heart disease. Am J Cardiol. 2003; 92:1007-1009. [PubMed: 14556887]

45. Hoeper MM, Spiekerkoetter E, Westerkamp V, et al. Intravenous iloprost for treatment failure of aerosolised iloprost in pulmonary arterial hypertension. Eur Respir J. 2002; 20:339-343. [PubMed: 12212965]

46. Rimensberger PC, Spahr-Schopfer I, Berner M, et al. Inhaled nitric oxide versus aerosolized iloprost in secondary pulmonary hypertension in children with congenital heart disease: Vasodilator capacity and cellular mechanisms. Circulation. 2001; 103:544-548. [PubMed: 11157720]

47. Winterhalter M, Simon A, Fischer S, et al. Comparison of inhaled iloprost and nitric oxide in patients with pulmonary hypertension during weaning from cardiopulmonary bypass in cardiac surgery: A prospective randomized trial. J Cardiothorac Vasc Anesth. 2008; 22:406-413. [PubMed: 18503929]

48. Limsuwan A, Wanitkul S, Khosithset A, et al. Aerosolized iloprost for postoperative pulmonary hypertensive crisis in children with congenital heart disease. Int J Cardiol. 2008; 129:333-338. [PubMed: 18096256]

49. Galie N, Humbert M, Vachiery JL, et al. Effects of beraprost sodium, an oral prostacyclin analogue, in patients with pulmonary arterial hypertension: A randomized, double-blind, placebocontrolled trial. J Am Coll Cardiol. 2002; 39:1496-1502. [PubMed: 11985913]

50. Badesch DB, McLaughlin VV, Delcroix M, et al. Prostanoid therapy for pulmonary arterial hypertension. J Am Coll Cardiol. 2004; 43:56S-61S. [PubMed: 15194179]

51. Barst RJ, McGoon M, McLaughlin V, et al. Beraprost therapy for pulmonary arterial hypertension. J Am Coll Cardiol. 2003; 41:2119-2125. [PubMed: 12821234]

52. Kermode J, Butt W, Shann F. Comparison between prostaglandin E1 and epoprostenol (prostacyclin) in infants after heart surgery. Br Heart J. 1991; 66:175-178. [PubMed: 1883670] 


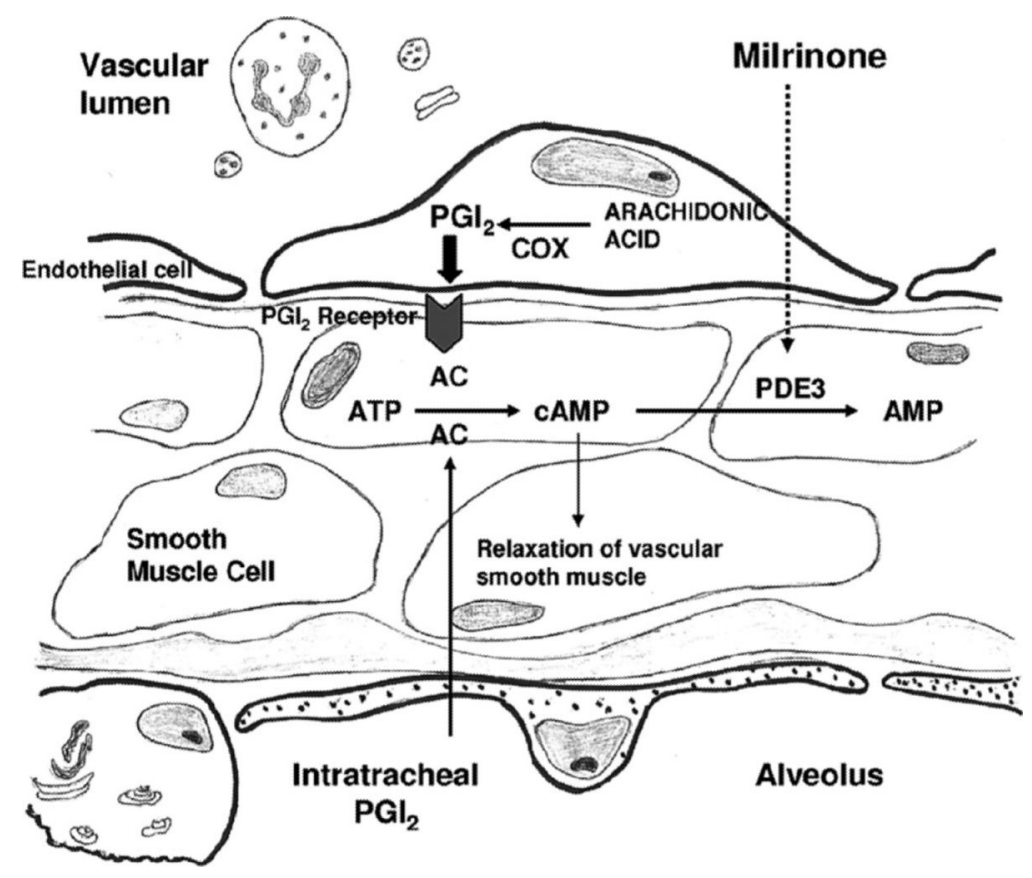

Figure 1.

Signal transduction pathway of the prostacyclin $\left(\mathrm{PGI}_{2}\right)$-cyclic adenosine monophosphate $(c A M P)$ pathway. Both $\mathrm{PGI}_{2}$ and milrinone, a $P D E 3$ inhibitor, increase cAMP by different mechanisms. $C O X$, cyclooxygenase; $A C$, adenylate cyclase; $A T P$, adenosine triphosphate. Reprinted with permission from Rashid et al (7). 


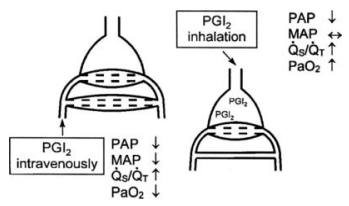

Figure 2.

Prostacyclin $\mathrm{I}_{2}\left(\mathrm{PGI}_{2}\right)$ given intravenously nonselectively dilates the pulmonary vasculature and may worsen ventilation/perfusion matching. In contrast, inhaled $\mathrm{PGI}_{2}$ may improve ventilation/perfusion matching by improving pulmonary blood flow to well-ventilated regions of the lung. $P A P$, pulmonary artery pressure; $M A P$, mean arterial pressure; $Q s / Q t$, intrapulmonary shunt. Reprinted with permission from Max and Rossaint (23). 


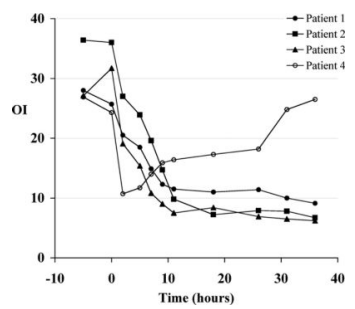

Figure 3.

Effect of inhaled prostacyclin $\mathrm{I}_{2}\left(\mathrm{PGI}_{2}\right)$ on oxygenation index $(O I)$ in term neonates with persistent pulmonary hypertension of the newborn receiving inhaled nitric oxide. Inhaled $\mathrm{PGI}_{2}$ decreased OI within $2 \mathrm{hrs}$ except in one patient (patient 4) who was later found to have alveolar capillary dysplasia. Reprinted with permission from Kelly et al (25). 


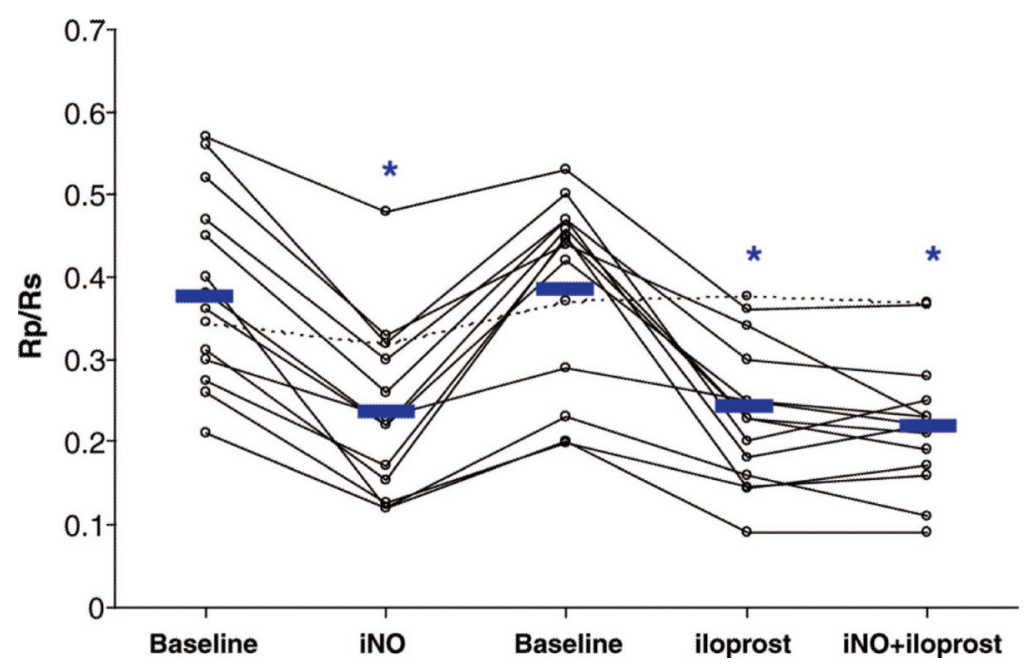

Figure 4.

In children with pulmonary arterial hypertension associated with congenital heart disease, inhaled nitric oxide $(i N O)$, and inhaled iloprost lowered the pulmonary vascular resistance/ systemic vascular resistance ratio $(R p / R s)$ compared with baseline. There was no additive effect of iNO to inhaled iloprost. Reprinted with permission from Rimensberger et al (46). 


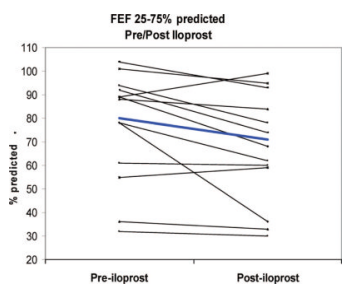

Figure 5.

Effects of acute inhalation of iloprost in 13 children with pulmonary arterial hypertension. At baseline, mean mid-volume forced expiratory flow $(F E F, 25-75 \%)$ was $82 \%$ of predicted (range, 32\%-119\%). After iloprost inhalation, mean FEF $25 \%$ to $75 \%$ decreased to $72 \%$ of predicted $(p=.03)$. In five $(38 \%)$ of 14 patients, FEF $25 \%$ to $75 \%$ decreased by $>15 \%$ (range, $-53 \%$ to $-17 \%$ ). Reprinted with permission from Ivy et al (40). 

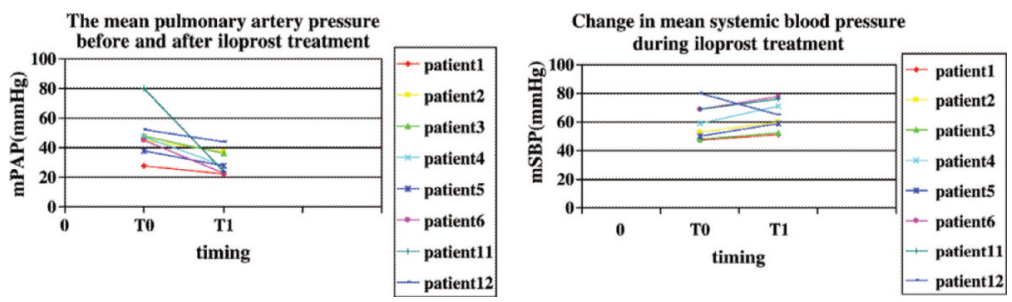

Figure 6.

Effect of inhaled iloprost in 12 children with postoperative congenital heart disease. Iloprost lowered mean pulmonary artery pressure $(m P A P)$ without lowering mean systemic blood pressure $(m S B P)$. Reprinted with permission from Limsuwan et al (48). 